\title{
Relevance of Genotyping for the Clinical Management, Transmission and Control Programs of Tuberculosis
}

Olimpia Nicolaescu?

\begin{abstract}
Tuberculosis (TB) has re-emerged over the past three decades worldwide. Molecular epidemiology (ME) is very usefulin thestudy of the phenotypic variation among strains, tracking the geographic distribution and clonal expansion of specific strains, to evaluate the transmissibility, virulence, and immunogenicity of different lineages of the organism. ME studies over the last three decades have contributed by answering long standing questions, such as the proportion of cases attributable to recent transmission, risk factors for recent transmission, the occurrence of infection with multiple strains of Mycobacterium tuberculosis (Mtb), the proportion of recurrent TB cases attributable to re-infection and a more precise quantification of mixed infection. In the laboratory, ME can be used to identify cross contamination. Many new DNA typing methods have been proposed after the initialintroduction of restriction fragment length polymorphism (RFLP) in 1993 which is still in use. Most of the newer DNA typing methods are polymerase chain reaction (PCR) based. Since genotyping continues to unravel the biology of mycobacteria,it offers enormous promise in the fight against and prevention of the diseases caused by this pathogen.
\end{abstract}

Keywords: Mycobacterium tuberculosis, molecular epidemiology, genotyping, transmissibility, drug resistance, risk factors, tuberculosis control programs.

\section{Rezumat}

Tuberculoza (TB) a redevenit o problemă de sănătate publică în ultimele trei decenii peste tot în lume. Epidemiologia moleculară (ME) este foarte utilă în studiul variațiilor fenotipice ale tulpinilor, urmărirea distribuției geografice și expansiunea clonală a tulpinilor specifice, evaluarea transmisibilității, virulenței și imunogenicității diferitelor filiații ale microorganismului. Studiile de ME din ultimele trei decenii au contribuit la elucidarea unor probleme vechi, cum ar fi proporția de cazuri ce pot fi atribuite unei transmisii recente, factorii de risc pentru o transmisie recentă, circumstanțele apariției unor infecții multiple cu Mycobacterium tuberculosis (Mtb), proporția de TB recurente atribuabile reinfecției și o cuantificare mai precisă a infecțiilor mixte. În laborator, ME poate fi utilizată pentru a identifica contaminarea încrucișată. Au fost propuse multe metode noi de tipizare ADN după introducerea initială a polimorfismului lungimii fragmentului de restricție (RFLP) în 1993, metodă ce se folosește încă. Cele mai multe metode noi de tipizare a ADN se bazează pe reacția de polimerizare în lanț (PCR). Dacă genotiparea va continua să aducă lămuriri asupra biologiei micobacteriilor, va oferi oportunități enorme în lupta de prevenire a bolii cauzate de acest patogen.

Cuvinte cheie: Mycobacterium tuberculosis, epidemiologie moleculară, genotipare, transmisibilitate, chimiorezistență, factori de risc, programe de control a tuberculozei.

1 Department of Pneumology, “Victor Babes" Clinical Hospital of Infectious and Tropical Diseases, Bucharest, Romania

\section{Corresponding author:}

Olimpia Nicolaescu, Department of Pneumology, "Victor Babes" Clinical Hospital of Infectious and Tropical Diseases, Bucharest, Romania.

E-mail: olimpia_nicolaescu@yahoo.com 


\section{INTRODUCTION}

More than 130 years after the discovery of its causative agent, TB still produces nearly 9 million new infections and 1.5 million deaths every year (one-quarter among them are patients co-infected with human immunodeficiency virus - HIV $)^{1}$. The incidence of TB ranges from less than 10 per 100.000 in North America to 100 - 300 per 100.000 in Asia and Western Russia, to over 300 per 100.000 in Southern and Central Africa. In several regions of the world, the rise of incidence is linked to the increasing impact of HIV epidemics, drug resistant TB and deficiencies of current TB control programs. These reasons determined WHO to declare TB a global emergency in $1993^{2}$.Despite the availability ofeffectiveanti-TB chemotherapy for over 65 years, TB remains a major global health problem. As such, there is a need for new therapeutics, diagnostics,

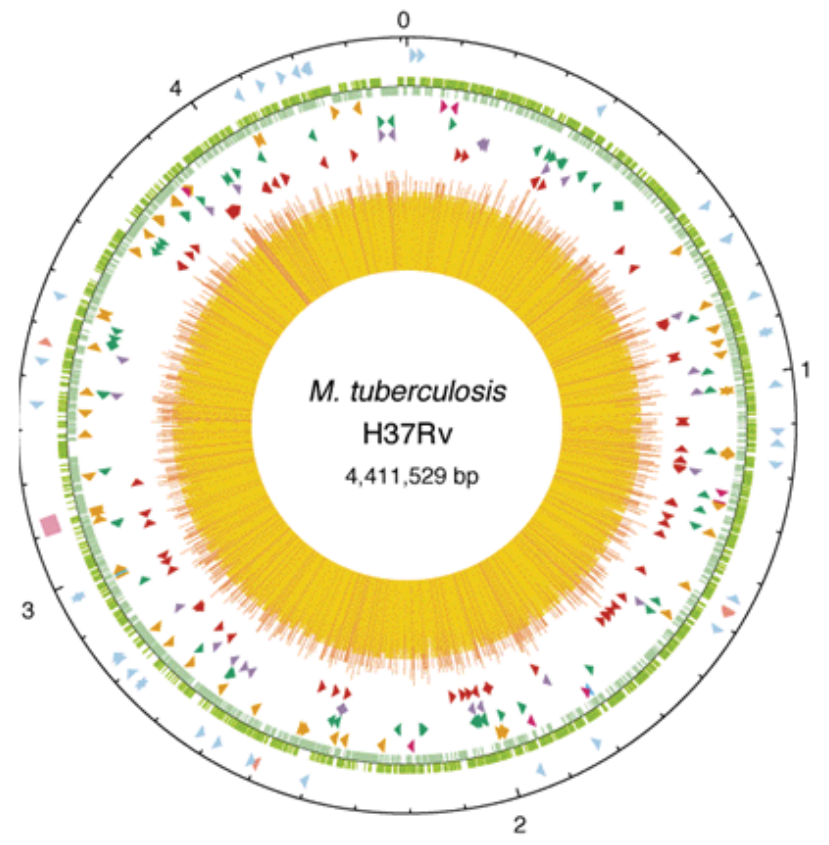

Figure 1. A diagrammatic representation of the MtbH37Rv genome (Cole ST et al. 1998).

and vaccines in conjunction with improvedoperational guidelines to enhance current TB control strategies.

By the early 1990's, when molecular fingerprinting first appeared, many questions in TB epidemiology remained unresolved. They included the relative contributions of reactivation and primary disease in areas of high and low prevalence, risk factors for recent infection and/or primary disease, and the occurrence and frequency of exogenous re-infection. More recent issues include the impact of HIV co-infection on transmission, the infectivity of smear-negative TB, the relative transmissibility of different strains, and other phenotypic differences among strains of $\mathrm{Mtb}^{3}$. In recent years, changes in the socio-epidemiological scenarios generated by immigration have revealed new challenges in ME. The key questions include comparison of the role of recent transmission with that of reactivation/importation in immigrant TB cases, the impact of potential importation of previously unidentified $\mathrm{Mtb}$ strains and cross-transmission between cases from different nationalities. Without the support of $\mathrm{ME}$, these questions would prove difficult to answer ${ }^{4}$.

\section{GENOME OF MYCOBACTERIUM TUBERCULOSIS}

The complete genome of $\mathrm{MtbH} 37 \mathrm{Rv}$ was published in 1998. This revealed a circular genome with 4.4 million base pairs (bp) containing approximately 4000 genes see Figure 1. The genome of Mtbis guanine-cytosine $(\mathrm{G}+\mathrm{C})$ rich $(65.6 \%)$, a feature that has been associated more often with aerobic prokaryotes.

It was demonstrated that Mtbpossesses all the genes necessary to synthesize essential amino- acids, vitamins and enzyme co-factors. It was noted that there isa high proportion of genes encoding enzymes involved in lipogenesis and lipolysis. The tuberculous bacillus possesses enzymes used in energy cycles, in aerobic, microaerophylic and anoxic electron transfer and is capable of surviving in a number of different environments including the oxygen rich lung, the macrophage and at the centre of caseating granuloma (Cole ST et al. 1998).

Although the mycobacterial species of the Mtb are highly similar to each other on deoxyribonucleic acid (DNA) level, Mtb members differ widely in terms of host tropism, phenotype and pathogenity. Genotyping methods have enlarged our understanding of phylogenetic relations and evolutionary origin of the members of the $\mathrm{Mtb}^{6}$.

\section{GENOTYPING METHODOLOGIES}

Genotyping methods are based on the analysis of chromosomal DNA of the Mtb. An ideal typing method should be highly discriminatory, easy toperform, fast and inexpensive and should generate results that arereproducible within a laboratory and between laboratories. It should be able to analyze very small quantities of bacterial material,preferablywithout the need for culturing, at the very earlystages of diagnostic and epidemiologic investigations. 
The following are the genotyping methodologies based on repetitive regions of the Mtbchromosome mostly used worldwide ${ }^{7}$ :

- IS6110-based restriction fragment length polymorphism (RFLP) analysis.

- Spoligotyping.

- Mycobacterial interspersed repetitive units (MIRU) analysis.

\subsection{IS6110-RFLP methodology}

IS6110 was initially described in 1989. Insertion sequences (IS) are small mobile genetic elements, with $1355 \mathrm{bp}$, that are widely distributed in most bacterial genomes ${ }^{8}$. It is exclusively present in the Mtb human TBand is also involved in drug resistance mechanisms $s^{3,9}$. Mtbstrains with identical IS6110-RFLP profiles isolated from different patients are generally considered to correspond to recent transmission events. Consistently, strains identified in outbreaks with the same IS6110RFLP patterns have revealed that clustering is associated with identical risk for transmission ${ }^{1}$.

IS6110-based typing is the most widely applied genotyping method in the molecular epidemiology of Mtb and is the gold standard to which other methods are currently compared ${ }^{9}$.

An internationally accepted, standardized protocolfor RFLP typing of the Mtb using IS6110 was published in 1990 and is still used today. Between 0-25 copies of IS6110 are found in almostall strains of MTBC and it is notknown to be present in other organisms. Strains of Mtbdiffer in their position and number of IS6110 copies and their distribution is highly variable in the genome. Thisvariability is exploited to distinguish between strains ${ }^{10}$. Applications include: phylogeny studies, detection of laboratory error/cross contamination, detection of mixed infection and provides best resolution for the analysis of W-Beijing isolates ${ }^{8}$.

Though IS6110 RFLP typing is the gold standardfor typingstrains of Mtb, it has severaldisadvantages: requires an amount of high quality DNA that can only be extracted from a large number of bacteria grown from clinical material, slow turnaround time (30-40 days), process is laborious, cannot be used to reliably type isolates with $\leq 6$ IS6110 insertions. Strains with fewer than six IS6110 insertion sites have a limited degree of polymorphism, and supplementary methods of genotyping are used in these cases ${ }^{10,11}$.

\subsection{Spoligotyping}

The Mtb genome contains multiple direct repeated (DR) regions of $36 \mathrm{bp}$, interspersed with non-repetitive spacer sequences of 34 to $41 \mathrm{bp}$ which constitute
DVR (direct variable repeat); both the DR region and the spacers have shown little variation among strains. Deletion of one or more DVR and duplication of DVR are the mechanisms which generate the variation among different strains. All of these changes generated in the DR locus are the foundation for the development of the spoligotyping methodology, a PCR-based $\operatorname{method}^{7}$.

It is the simplest technique for Mtb strain genotyping, data are presented in binary format (positive or negative), allowing inter- and intra-laboratory comparisons, can be performed directly on cell lysate, no DNA purification is required, can be performed on nonviable bacteria ${ }^{12}$. It is economical, easy to perform and a rapid method of typing the Mtb. This characteristics makes it a candidate for use in poor resource situations. The ability to perform spoligotyping directly on sputum samples makes it applicable in acute clinical situations ${ }^{9}$. It is ideal for a first-step analysis ofMtb, particularly in regions with diverse populations, for $\mathrm{ME}$ studies and detection of laboratory error/cross contamination.Nonetheless, the discriminatory powerof this method is less than that of IS6110 typing, itcannot recognize mixed infections and it is less informative in regions with predominant or endemic strains; e.g., WBeijing in China, Southeast Asia, and Russia ${ }^{11}$.

Spoligotyping is the backbone of the largest public available database, SpolDB4, which, on its release in 2006, described a total of 1939 clustered patterns representing 39.295 strains from 122 countries. Developed and housed at Pasteur Instituteof Guadeloupe, SpolDB4 has recently evolved to a multimarker database (SITVIT2) that contains genotyping information on nearly $75.000 \mathrm{Mtb}$ isolates from 160 countries, including MIRU-VNTRs on about 15.000 isolates.

\subsection{MIRU-VNTR methodology}

DNA segments contain "tandem repeated" sequences in which the number of copies of the repeated sequence varies among strains. Variable Number Tandem Repeat (VNTR) sequences have emerged as valuable markers for genotyping.Mycobacterial interspersed repetitive units (MIRU) are a class of tandem repeated sequences. There are a total of $41 \mathrm{MIRU}$ loci.Of the 41 different MIRU loci, 12 loci were identified as hyper variable repetitive units ${ }^{13}$.

MIRU-VNTR is a PCR-based method that uses "tandem repeated" sequences in which the number of copies of the repeated sequence varies among strains. Theresults are reported as 12 numbers, each one corresponding to the number of repetitions. Recently a systemwas proposed which includes typing of 24-loci 
MIRU-VNTR combining multiplex PCRanalysis or a DNA analyzer based on fluorescence with the computer automation of genotyping ${ }^{7}$.

The discriminatory power of MIRU genotyping is almost as great as that of IS6110-based genotyping. Unlike IS6110-based genotyping, MIRU analysis can be automated and thus can be used to evaluate large numbers of strains, yielding intrinsically digital results that can be easily catalogued on a computer database. A web-site has been set up so that a worldwide database of MIRU patterns can be created. MIRU genotyping istechnically simpler than IS6110-based genotyping and can be applied directly to cell lysatecultures without DNA purification, although is less discriminatory than IS6110RFLP genotyping11. Applications include population genetic/evolutionary investigations, the potential for real-time genotyping and it can be used to identify mixed infections ${ }^{8,14}$.

\section{MOLECULAR EPIDEMIOLOGY SUPPORT FOR CONTROLLING TUBERCULOSIS}

\subsection{Study of M. tuberculosis transmission dynamics}

$\mathrm{ME}$ investigations have beenvery useful in providing understanding of the transmission dynamic of TB within a community. These studies are based upon the premisethat patients infected with strains showing identical fingerprints, termed "clustered cases", are the resultof recent transmission, whereas those infected withisolates with unique RFLP patterns are presumed torepresent remote transmission and thus reactivationof strains acquired in the more distant past ${ }^{9,15}$.

A basic principle was that the strains of $\mathrm{Mtb}$ who infected the contactsare likely to have the samedrug susceptibility pattern as the index case. Thishypothesis was tested in a fingerprint study of index and contact cases, which were bothdiagnosed with TB. Thirty percent of pairs had different fingerprints,demonstrating that the contact was infectedby an unidentified third person. This illustrates thattransmission links are often more complex than thoseassumed by conventional epidemiology. Similarly, acontact investigation among five large clusters inthe Netherlands showed that transmission occurred afteronly transient contact, contrary to the conventionalview that $\mathrm{TB}$ is usually acquired followingprolonged exposure to an infectious case.

The imprecision of contact-tracing investigations has been highlighted by several reports (studies con- ducted in San Francisco and Baltimore)that have indicated that limitedor casual contact is sufficient for Mtbtransmission.

When a second case is recognized as part of a contact investigation, it is generally assumed that the two cases show the same strain of Mtb. ME studies have established that this is not always true. Of 211 contacts evaluated in San Francisco, the contact cases were infected with the same strain of Mtb in 70\%, but had unrelated strains in the rest of $30 \%$. Unrelated infections were more common among abroad-born, particularly Asian, contacts. Similarly, in a study from Denmark, among 22 cases in contact with one or more persons with TB, six $(27 \%)$ cases among the contacts had different genotype patterns from the presumed source case; in two instances the case index and thecontact lived in the same household ${ }^{15}$.

\subsection{Identification of unsuspected transmission}

Studies of the ME of TB have elucidated both suspected and unsuspected transmission. Use of genotyping has identified contacts that were not found via traditional contact investigations, as well as networks and places of transmission that were not originally suspected. In addition, genotyping has distinguished between true secondary cases and coincidental, active TB among contacts ${ }^{15}$.

ME studies have identified many unsuspected community outbreaks of TB, resulting in focused public health interventions.For example, in Los Angeles, homelessshelters were identified as major sites of TB transmission andin San Francisco, the transmission index(defined as the number of cases of TB generated by a single source case), was seven times higher among U.S.- born African-Americans as among U.S.-born whites or Hispanics. Thisdifferencewas not due to an increased prevalence ofHIV infection or of acid-fastpositive sputum smears among African-Americans but may havebeen related to delays in seeking medical attentionor to social factors such as over-crowding that facilitates the transmission of disease ${ }^{11}$.

The identification of secondary cases of TB among those previously unsuspected demonstrates the limitationsof traditional contact investigation. In one of the first genotyping studies, investigators in Switzerland described the transmission of TB among members of a defined social group (drug addicts, homeless persons, and alcoholics) and documented its spread to the general population. These studies demonstrate that once a connection is suspected or identified, valuable information can be obtained by re-evaluating contacts ${ }^{15}$. 


\subsection{Evaluation of transmission in specific populations/groups}

The impact of immigrant subpopulations on theTB epidemiology in acommunity has been perceived as an importantpublic health issue in developed countries. Forexample, during 1986-1997, the number of TB cases diagnosed in abroad born persons in theUSA increased by $56 \%$. These statistics suggest thatimmigrants could transmit TB to thenative population, but opinions are different with this respect. A study from San Francisco described two parallel epidemiological patterns of TB in foreign-born and US-born populations. Most foreign-born individuals develop TB from reactivation, whereas $20 \%$ of US-born casesdeveloped TB from recent infection.

In Europe, according tothe European Center for Disease Control and Prevention (ECDC), in 2012 the overall proportion of TB cases of foreign originin the European Unionwas 26.8\% with some northern European countries showing rates as high as $85.4 \%$. For example, in 2013, Palermo, Italy, and its province, has registered about 29000 resident immigrants, doubling the proportion reported at the beginning ofthe 2000's. The increasing heterogeneity of the population, now accounting for more than 50 countries, from the African continent to Latin America, from Asia to East Europe is represented primarily by the wide heterogeneity of the Mtb strains detected in the years 2004-2012 with the identification of 11 lineages and 35 families-subfamilies, comparing with that of the years 1994-2000, when only seven lineages could be identified after reanalyzing the old spoligotyping dataset. Not only was the recent number of lineages higher, but the distribution of isolates was significantly different between the two consecutive periods mirroring the increasing contribution of isolates from foreign-born TB patients ${ }^{16}$.

\subsection{Identification of transmission in a given setting}

Increased surveillance with prompt diagnosis and appropriate therapy in settings in which there are many HIV-infected persons, in hospitals, prisons, schools and homeless shelters is now resulting in an overall decrease in TB transmission.

Analysis of isolates by IS6110 RFLP demonstratedthat newly acquired TB infection in HIV-infectedpatients spread rapidly and progressed within3 months of exposure to disease, demonstrating theparticular vulnerability of HIV-infected individualstoexogenousTBinfection. Also, HIV infection exerts immense influence on the natural course of TB disea- se. Individuals with latent Mtbinfection who contract HIV are at risk to develop active TB at a rate of 7 to 10 per cent per year, compared to approximately 8 per cent per lifetime for HIV-negative individuals.

$\mathrm{ME}$ has also documented thepotential for spread of MDR strains amonghospitalized patients with HIVinfection. During one 43-month period, New York City accounted for almostone-quarter of all cases of MDR-TB in the USA.Most of these patients were infected with HIV and found to have acquired their MDR-TB duringtheirhospital-stay.

\subsection{Early detection of outbreaks}

Analysis of clinical isolates in certain areas can help determine if isolates share the same genotype, and they form a cluster. Additionally, there shouldbe analyzed factors such as place of residence, work, as well as the time spent in each of them.

Atlanta CDC genotypic guide studies propose three criteria for an TB outbreak ${ }^{7}$ :

- An increase in the expected number of TB cases;

- Transmission continues despite adequate control efforts by the TB program;

- The contact investigation has grown to a size that requires additional outside help.

If epidemiologic data suggest the occurrence of an outbreak of TB, genotyping of the isolates, in combination with an epidemiologic investigation, can help determine whether an outbreak has occurred or whether there is a coincidental occurrence of a large number of cases. This strategy can value the extent of the outbreak and guide public health measures to reduce disease transmission ${ }^{11}$.

\subsection{Identification of risk factors and groups at risk of $M$. tuberculosis infection}

Risk factors for TB attributable to recent transmission include male sex, being a young adult, being native (vs. foreign-born), urban residence, alcohol and drug abuse, being homeless, exposure to crowded settings, including prisons, and having pulmonary TB. HIV and MDR-TB were found to be risk factors in some settings, but not in others. On the contrary, the elderly in low-incidence countries have a much higher risk of TB attributable to endogenous infection than the young, so the proportion of TB in that age group attributable to recentinfection may be expected to be smaller than among the young. However, young age is also, in absolute terms, a risk factor for recently transmitted $\mathrm{TB}^{12}$.

Patterns of TB transmission differ greatly between settings, as they reflect an interplay between various 
factors, including existing TB control strategies, endemicity (the rate of clustering is lower in settings of low endemicity than in settings of higher endemicity), population density, subpopulations with lower TB immunity, migration patterns, geography, demography, and transmissibility of locally relevant Mtbcomplex strains. Genotyping data have given important clues about risk factors for TB transmission and can help to inform health authoritiesto plan adequate action to curb local TB transmission.

A ME study conductedover the period 2010-2013 on 945 positive culture TB patients living in Brusselsidentified classic risk factors for TB transmission such as being underprivileged (41.4\%), having a recent contact with a TB patient (23.2\%) or being asylum-seekers or undocumented immigrants (24.9\%). Having a previous history of TB was also confirmed to be a MDRTB predictor. Analysis of the MDR subgroup showed an association with Beijing strains (39.9\%) and native patientsof East-Europe $(40.7 \%)^{17}$.

\subsection{Discriminating recurrent TB due to exogenous reinfection and reactivation}

Before 1990, it was generally believed that, in low-incidence countries, most TB cases were attributable to endogenous reactivation of latent infection, and only a small proportion, about $10 \%$, would derive from recent transmission. Molecular techniques can help distinguish endogenous from exogenous infection.

Studies conducted in countries with different rates of TB incidence have demonstrated various levels of recurrent diseaseattributable to exogenous re-infection.

Ninety percent of TB cases in industrialized nations were sometime believed to result from a reactivation of infection acquired in the distant past. However, population-based genotyping indicatesthat recent transmission causes 20 to 50 percent of cases in urban areas.Continuedtransmission results from two major factors. First, there is a substantial rate of transmission amongcasual contacts in workplaces and other social settings even if contact was often limited. Second, in most cases, transmissionprobably precedes anti-TB therapy.Therefore, even after many years of global, directlyobserved therapy and high rates of treatment completion, studies have shown that one third of TB casesare still due to recent transmission.Furthermore, a large proportion of TB patients, generally request medical care long after symptomsdevelop, contributing to the spread of disease ${ }^{11}$.

The precise proportion of disease due to recent transmission or endogenous reactivation is variable and heavily dependent by a number of factors, including the annual rate of TB infection, the molecular method used, effective TB control programs, the size of the infected pool of individuals, age cohort effects, immigration history, population susceptibility (e.g., genetic susceptibility, HIV prevalence, BCG vaccination).

\subsection{Detection of laboratory error/cross- contamination}

Approximately 3 percent of patientsfromwhomMtbis apparently isolated inclinical laboratories do not have TB; thepositive cultures are due to cross-contamination. The occurrence of cross-contamination is mostlikely when acid-fast smears are negative and onlyone specimen is culture-positive.WhenMtbis isolated from a specimen, without an epidemiological or clinical explanation,laboratory cross-contamination should also be suspected.The isolates should be analyzed by reliable molecular typing techniques, and compared with specimens that were originally processed during the same time period. Many investigators used IS6110 RFLP typing, VNTR typing or spoligotyping to detect and evaluate laboratory cross-contamination ${ }^{10,11}$.

\subsection{Determination of geographic spread of strains}

There is increasing evidence that the genetic difference of Mtb is strongly associated with specific geographical locations. Thus, ME studies in a high TB incidence country may provide unique insights into dissemination dynamics and virulence of the pathogen ${ }^{2}$.

The lineages of Mtbare distributed worldwide, as shown below:

- Haarlem (H) - It is highly prevalent in Northern Europe, while it is less extended in the $\mathrm{Ca}$ ribbean and Central Africa, where it is thought to be introduced by the European colonization.

- Latin America and Mediterranean (LAM) - It is frequent in Mediterranean and Latin American countries.

- T Lineage - Comprised by modern strains of TB. This lineage is characterized "by default" and it includes strains which are difficult to classify into other groups.

- X lineage - It was identified in Anglo-Saxon cities, and it is highly prevalent in South Africa, less in Latin America. However, there is high presence of this genotype in Mexico, which can be explained by its proximity to the United States. The $\mathrm{X}$ lineage was the first group identified in Guadeloupe and the French Polynesia. 
- $\quad$ East African-Indian (EAI) - It is frequent in South East Asia, India, and eastern Africa.

- Central Asian (CAS) - It is highly prevalent in sub-Saharan countries and Pakistan. This lineage has also proved to be endemic in Sudan, sub-Saharan countries, and Pakistan. This spoligotype has numerous variants and subgroups such as CAS1-Kili (Kilimanjaro), CAS-Dar (Dar-esSalaam), and CAS-Delhi.

- Beijing - In terms of public health it continues to be a serious problem for TB control due to its high virulence and association with multi-drug resistance.

- MANU - It was subdivided into Manu 1 (absence of spacer 34), Manu 2 (absence of spacers 33-34), and Manu 3 (absence of spacers 34 to 36). It is a new family from India.

The most commonly cited andreviewed example of the geographical disseminationof a particular Mtb clone is that ofW-Beijing strains which is a MDRstrain, responsible for causingmany cases of $\mathrm{TB}$ and deaths attributable to TBamong patients and health care workers in nosocomialoutbreaks and other institutional settings in New YorkCity during the 1990s. This "Beijing family"strains were also detected in high proportions in Asia, the former Russian Federation and Estonia, Latin America.

The key finding of the study conducted in Cape Town - South Africa, which bears $28 \%$ of the global burden of HIV-related TB, was the associationbetween W-Beijingand HIV infection. This association persistedafter the control of a number of clinical factors and could bedue to either an increased pathogenicity or virulence of thestrain or an increased susceptibility of $\mathrm{HIV}$-infected patients tothese strains ${ }^{18}$.

At the Muñiz Hospital in Buenos Aires, Argentina, spoligotyping identified predominance of the Haarlem family among the MDR-TB cases (Mtb family responsible for the 1990s outbreak) as well as the LAM and $\mathrm{T}$ families ${ }^{19}$.

\subsection{Monitoring of transmission of drug-resistant strains}

Despite the implementation of multiple anti-TB therapies, a steady increase in the frequency of TB with single and multiple drug resistant Mtb strains has been reported throughout the world. In the early 1990s outbreaks of MDR-TB received global attention. Nosocomial outbreaks of MDR-TB have been reported in the USA, France and other countries. MDR and
$\mathrm{XDR}-\mathrm{TB}$ can give rise to potentially untreatable forms of disease. In addition mortality is significantly higher among persons infected with MDR and XDR strains than among those infected with sensitive strains. Moreover, patients with MDR and XDR-TB remain infectious for longer time thus increasing the risk of disease transmission.

Genotyping permits the evaluation of isolates with different patterns of drug susceptibility. Suchan evaluation may be helpful in cases in which the original organism developed drug resistance during or after antiTB therapy, the patient was re-infected with a different Mtbstrain, or cross-contamination is suspected. Genotyping the isolates fromthe patient and other isolates processed at the same time, can distinguish among these possibilities ${ }^{11}$.

The mechanisms of drug resistance for Mtb are chromosomal, caused by accumulation of one or more mutations in independent genes. Detection of drug resistance is performed by culturing Mtb in the presence of antibiotics. More recent methods are based on liquid media including the BACTEC radiometric and the Mycobacterial Growth Indicator Tube methods (MGIT). However, due to the long time period necessary to obtain results and laboriousness of these methods, molecular approaches have been proposed. These methods have an important role in identifying prevalent drug resistance mutations amongst Mtb population in a particular geographical location, make timely diagnosis of $\mathrm{Mtb}$ drug resistance and an adequate anti-TB therapy possible ${ }^{2}$.

There is no evidence of a lower risk of infectionamong contacts exposed to pulmonary MDR-TB patients as demonstrated by studies in Mexico, among South African gold miners ${ }^{20}$ and inthe Netherlands. Except in localized areas withpoor cure rates, and a high prevalence of HIV, it isunlikely that drug resistance strains spread fast.

It is possible that in patients with mixed infections, the drug resistance profile may be composed of strains with different susceptibilities (e.g., simultaneous infection with mono-INH- and mono-RIF- resistantstrains), leading to incorrect MDR resistance profiles. Therefore, genetic heterogeneity may require therapeutic targeting of both drug-resistant and drug-susceptible phenotypes, especially with first-line agents ${ }^{8}$.

\subsection{Detection of mixed infections among TB patients}

It has been understood from the recent reports that a single patient could be infected with more than one- 
strain of $\mathrm{Mtb}^{10}$. Mixed infection with different strains has also been identified with molecular techniques. Whereas, in low-incidence countries, the probability of multiple infection is expected to be low, in high-incidence countries this risk may be high. Evidence of multiple strains involved in TB disease has emerged in recent years. From TB patients in Cape Town, 19\% were infected with both a Beijing strain and a non-Beijing strain. Two studies in Taiwan found that, among TB patients, $3 \%$ and $11 \%$, respectively, were infected with a Beijing strain and a non-Beijing strain. In Malawi, $3 \%$ of patients were infected with strains of the LAM and non-LAM lineages.

\subsection{Quantification of the level of infectiousness amongsmear-negative patients}

It is generally believed that patients with $\mathrm{TB}$ whose sputum microscopic examination failsto detect acidfast bacilli (AFB) are significantly lessinfectious than those with positive smears. However,a ME study that comparedtransmission from AFB smear-positive and

\section{References}

1. Jagielski T., Minias A., van Ingen J., Rastogi N., Brzostek A., Zaczek A., Dziadek J.: Methodological and clinical aspects of the molecular epidemiology of Mycobacterium tuberculosis and other mycobacteria. ClinMicrobiol Rev 2016; 29: 239-290. doi:10.1128/CMR.00055-15

2. Ali A.: Mycobacterium tuberculosis and Molecular Epidemiology: An Overview.Journal of Microbiology Research 2014, 4(6A): 25-31. doi: 10.5923/s.microbiology.201401.04

3. Murray M., Nardell E.: Molecular epidemiology of tuberculosis: achievements andchallenges to current knowledge. Bulletin of the World Health Organization 2002; 80 (6): 477-482

4. deViedmaa D.G., Mokrousovc I., Rastogid N.: Innovations in the molecular epidemiology of tuberculosis. EnfermlnfeccMicrobiolClin. 2011; 29(Supl 1): 8-13. Document downloaded fromhttp://www.elsevier.es

5. Shorten R.J.: The Molecular Epidemiology of Mycobacterium tuberculosis in North London. A thesis submitted to University College London of the requirement for the degree of Doctor of Philosophy 2009

6. Viegas S.O.: Molecular characterization of Mycobacterium tuberculosis complex isolates in Mozambique. Thesis for doctoral degree (Ph.D.)Published by Karolinskalnstitutet. Printed by E-Print AB 2015. ISBN 978-91-7676-131-1

7. Orduz M.L., Ribon W.: Molecular Epidemiology of Tuberculosis. Chapter from the book Tuberculosis - Expanding Knowledge 2015. http://dx.doi.org/10.5772/59751 Downloaded from: http://www.intechopen.com/books/tuberculosis-expandingknowledge

8. Mathema B., Kurepina N.E., Bifani P.J., Kreiswirth B.N.: Molecular Epidemiology of Tuberculosis: Current Insights. CLINICAL MICROBIOLOGY REVIEWS 2006, 19 (4); pp. 658-685

9. Burgos M.V., Pym A.S.: Molecular epidemiology of tuberculosis. EurRespir J 2002; 20: Suppl. 36, pp. 54-65

10. Narayanan S.: Molecular epidemiology of tuberculosis. Review Article. Indian J Med Res 2004; 120: pp. 233-247

11. Barnes P.F., M.D., Donald Cave D.: Molecular Epidemiology of Tuberculosis. N Engl J Med 2003;349: pp. 1149-56

12. Borgdorff M.W., van Soolingen D.: The re-emergence of tuberculosis: what have we learnt from molecular epidemiology? Clin -negativepatients suggested that AFB smear-negative patientswere responsible for $21 \%$ of TB transmittedin the city of San Francisco. Thus intensifying TB control measures for smearnegativecases could significantly reduce the transmission of TB.

\section{CONCLUSIONS}

Molecular methods could enhance understanding of tuberculosis transmission dynamics and could be used to improve current control programs locally and globally. Genotyping information of Mtb strains, together with epidemiologic investigations, may provide important information about the spread of Mtb strains by identifying factors related to transmission and progression to TB disease. This in turn could greatly assist in formulating strategies for control of TB. Moreover, rapid detection of drug resistance using molecular methods in Mtb isolates of TB patients, in conjunction with routine susceptibility testing, could further assist in timely and adequate use of anti-TB therapy thusplaying a pivotal role in treatment and containment of sensitive as well as drug resistant TB patients.

Microbiol Infect 2013; 19: pp. 889-901

13. Desikan S., Narayanan S.: Genetic markers, genotyping methods \& next generation sequencing in Mycobacterium tuberculosis. Indian J Med Res June 2015; 141:pp 761-774. doi:10.4103/ 0971-5916.160695

14. Alonso-Rodríguez N., Martínez-Lirola M., HerránzM.,SanchezBenitez M, Barroso P., Bouza E., de Viedma D.G.: Evaluation of the new advanced 15-loci MIRU-VNTR genotypingtool in Mycobacterium tuberculosis molecular epidemiology studies. BMC Microbiology 2008; 8: 34. Available from: http://www.biomedcentral.com/1471-2180/8/34

15. Daley C.L.,Kawamura L.M.: The role of molecular epidemiology in contact investigations:a US perspective. INT J TUBERC LUNG DIS 2003; 7(12):S458-S462

16. Bonura C., Gomgnimbou M.K., Refrégier G., Aleo A.,Fasciana T.,Giammanco A., Sola C., Mammina C.: Molecular epidemiology of tuberculosis in Sicily, Italy: what has changed after a decade? BMC Infectious Diseases 2014, 14:602. http://www. biomedcentral.com/1471-2334/14/602

17. Vluggen C., Soetaert K., Groenen G., Wanlin M., Spitaels M., Arrazola de Oñate W., et al. : Molecular epidemiology of Mycobacterium tuberculosis complex in Brussels, 2010-2013. PLOS ONE 2017; 12(2): e0172554. doi:10.1371/journal

18. Middelkoop K.,Bekker L.G.,Mathema B., Shashkina E., Kurepina N., Whitelaw A.,FallowsD., Morrow C., Kreiswirth B., Kaplan G. Wood R.: Molecular EpidemiologyofMycobacteriumtuberculosisin a South African Communitywith High HIV Prevalence. The Journal of Infectious Diseases 2009; 200: pp. 1207-1211

19. Gonzalo X., Ambroggi M., Cordova E., Brown T., Poggi S., Drobniewski F.: Molecular Epidemiology of Mycobacterium tuberculosis, Buenos Aires, Argentina. Emerging Infectious Diseases 2011; 17 (3) Available from:www.cdc.gov/eid

20. Mathema B., Lewis J.J., Connors J., Chihota V.N., Shashkina E., van der Meulen M., Graviss E.A., Ha N.P., Kreiswirth B.N., Grant A.D., Fielding K.L., Dorman S.E., Churchyard G.J.: Molecular Epidemiology of Mycobacterium tuberculosis among South African Gold Miners. Ann Am ThoracSocVol 12, No 1, pp 12-20, Jan 2015. doi: 10.1513/AnnalsATS.201404-1500C. Internet address: www.atsjournals.org 